\title{
MAQUILADORAS, MOVIMIENTOS DE CAPITALES Y MIGRACIÓN
}

Henry Veltmeyer

Unidad Académica en Estudios del Desarrollo, UAZ

\begin{abstract}
La actual ola de globalización libera el comercio internacional y los movimientos de capitales, no los movimientos de mano de obra. Los economistas del desarrollo consideran que la globalización ocurre a expensas del Estado-nación, que pierde la capacidad de dictar y ejercer el poder político, determinar y legislar la política macroeconómica, ante el poder de los gobiernos y organizaciones internacionales. Esto no fue así en el caso del trabajo. Los países del Norte son los principales receptores de flujos migratorios, refugiados económicos (familias y personas que buscan mejorar su empleo e ingresos) y refugiados políticos (personas que migran por razones políticas). Los gobiernos de los países receptores no han renunciado al poder de regular el flujo de migrantes; tampoco han sido presionados para hacerlo, como lo han sido en el caso del capital y el comercio, pues el Banco Mundial, el Fondo Monetario Internacional y la Organización Mundial del Comercio han impuesto "la reforma estructural" en la política gubernamental.
\end{abstract}

$\mathrm{D}$ esde la década de 1980, la mayoría de países del mundo ha seguido una estrategia de integración a la economía mundial. La estrategia podría llamarse "globalización neoliberal", con referencia al "nuevo modelo económico" que utiliza como guía política un programa de "reformas estructurales" orientado a ajustar las economías nacionales a los dictados del nuevo orden mundial. El sello distintivo de este orden era la libertad económica - para liberalizar los flujos comerciales y financieros y desregular los mercados de mercancías, trabajo y capital-, que supone la eliminación de las restricciones a la inversión extranjera y la libre circulación de mercancías. Curiosamente, el único factor de la producción mundial que no se liberó del control gubernamental y al que no se le permite circular y moverse libremente en todo el mundo era la mano de obra, distinguiendo el movimiento de globalización de los años 1980 y 1990 de un periodo anterior de la globalización: desde 1870 hasta la Primera Guerra Mundial, caracterizado por el libre comercio, la exportación de capital-dinero y un enorme flujo de mano de obra migrante, la mayor parte del viejo mundo de Europa al nuevo mundo de América, tanto en el sur (españoles y portugueses) como en el norte (principalmente británicos) .

La globalización tiene que ver con el libre comercio internacional de productos y servicios, y la libre circulación de mano de obra, la principal fuente de valor añadido a la producción económica, así como con "capital" (el dinero invertido en el proceso de producción para generar ganancias para los inversionistas). En teoría, la idea es que el libre mercado - el libre movimiento de producción, comercio, capital y trabajo- es el mejor o más eficiente medio para decidir quién obtiene qué, en términos de riqueza e ingreso (el producto social comercializado a nivel global), y que los intentos gubernamentales de restringir el comercio internacional o los movimientos de capitales y mano de obra, los "factores básicos de la producción" (tierra, recursos naturales y tecnología), distorsionarían el funcionamiento adecuado de las leyes del mercado, generando todo tipo de problemas, tales como la falta de un robusto crecimiento económico (aumento de la producción nacional o del PIB), la informalización del trabajo, el desempleo y la pobreza.

\section{Migrante laboral y mercado de trabajo}

Por diversas razones, los migrantes se sienten motivados a abandonar su patria para buscar una mejor vida y más oportunidades. Los economistas de la migración detectan factores de "expulsión" y de "atracción", con referencia a las condiciones objetivas y subjetivas que están detrás de la decisión de migrar. Sin embargo, el flujo migratorio dominante involucra a individuos y familias en pos de mejores oportunidades de empleo y trabajo: buscan medios de vida e ingresos mayores por la venta de su fuerza de trabajo en el mercado laboral. En otras palabras, son los trabajadores migrantes.

El actual flujo internacional y mundial de trabajadores migrantes es voluminoso a pesar de las restricciones impuestas por los gobiernos de los países receptores. Se estima que, en el nuevo milenio, los flujos globales anuales de migrantes que se desplazan por diversas razones, principalmente económicas y políticas, a través de las fronteras nacionales es de millones de personas (la entrada de inmigrantes en Europa y Estados Unidos en conjunto supera los cinco millones al año), y que el trabajo (es decir, los trabajadores migrantes) constituyen por lo menos dos terceras partes de este flujo. ${ }^{1}$ El otro tercio está compuesto por familias y personas que optan por migrar, o son empujadas a hacerlo por razones medioambientales o políticas, esto 
es, los refugiados ambientales (eluden las consecuencias de un desastre natural o la destrucción del entorno para la actividad económica) o, más probablemente, los refugiados que pretenden escapar de las condiciones políticas en sus países o solicitar asilo político.

En cuanto a los trabajadores migrantes, la cuestión más crítica respecto de a dónde emigrar es el mercado de trabajo en el país receptor, es decir, el grado en que el tipo de trabajo que pueden ofrecer es demandado. Como una cuestión de hecho, los investigadores han descubierto -y los migrantes lo saben muy bien- que los gobiernos del país receptor discriminan activamente las formas de trabajo que no están en la demanda y admiten o promueven el flujo de mano de obra migrante con alta demanda.

Sin embargo, el estado del mercado laboral no es el único factor estructural detrás de la decisión en cuanto a dónde emigrar. Por un lado, los migrantes a menudo no están informados sobre las condiciones del mercado; por otro, el modelo actual de flujo de mano de obra migrante sugiere que existen otros factores que orientan los flujos laborales. Por ejemplo, hay un fuerte patrón de conexión entre lo que podría llamarse el imperialismo y el colonialismo económico: los sudamericanos, centroamericanos y mexicanos tienden predominantemente a emigrar hacia el norte, a Estados Unidos y -aunque en menor medida- a Canadá. Estados Unidos, por supuesto, ha sido históricamente el poder económico dominante en América Latina. Los migrantes del norte de África y África subsahariana se dirigen principalmente a Europa del Norte, por lo general a los países que eran más activos en su pasado colonial.

Por supuesto, la accesibilidad, contigüidad o proximidad -y por tanto el costo- son factores involucrados; otro, son los patrones migratorios anteriores: los migrantes siguen los movimientos anteriores a través de miembros de su familia o de su comunidad, y optan por emigrar hacia las zonas donde se ha formado una comunidad de migrantes de su país.

De hecho, la investigación sugiere que la existencia de anteriores flujos migratorios es un factor crítico o importante para tomar decisiones individuales o familiares sobre a dónde emigrar. Las familias o personas prefieren emigrar hacia áreas, países y ciudades donde están asentadas comunidades importantes de trabajadores migrantes con los que pueden identificarse o relacionarse.

La mayoría de los migrantes de Zacatecas, el estado mexicano con el mayor flujo de salida de trabajadores migrantes como porcentaje de la población, emigra a Chicago y Los Ángeles, donde existen comunidades importantes y clubes de migrantes formados por generaciones anteriores de trabajadores zacatecanos migrantes. ${ }^{2}$ De hecho, se han establecido vuelos directos diarios entre estas ciudades para manejar el constante flujo transfronterizo de familias migrantes de origen zacatecano.
Los estudios sobre los flujos de fuerza de trabajo migrante vis-à-vis los estudios del mercado laboral no muestran un patrón consistente sobre los factores de atracción laboral. El factor determinante parece ser la demanda de trabajo y el ajuste o respuesta de la política gubernamental a los cambios en la demanda. Por lo tanto, la demanda de fuerza de trabajo barata en el sector agrícola de la economía en los estados del sur se ha basado en una fuente inagotable de "braceros", jornaleros en la cosecha de frutas, una fuente de trabajo muy barata y agotadora para la que existe una oferta nacional insuficiente y un suministro dispuesto al otro lado de la frontera.

Tanto los factores de demanda como los de oferta -el estira y afloja- parecen influir en la creación de uno de los mayores flujos de fuerza de trabajo migrante estacional y permanente en el mundo -documentada o indocumentada-. El mismo patrón y las mismas condiciones se encuentran en el norte de Europa, que atrae la mano de obra que viene del sur, y, más recientemente, de Europa del Este, el Cercano Oriente (Turquía, Irán, etcétera) y el continente africano. Una vez más, es posible observar los efectos de los lazos familiares intergeneracionales y patrones coloniales en tanto los turcos, por ejemplo, prefieren ir a Alemania, y los norteafricanos a Italia y España, ahora que estos países han avanzado en su nivel de desarrollo.

Sin embargo, el estado del mercado de trabajo - la demanda de formas específicas de trabajo- es claramente un factor importante, si no determinante, por lo menos con respecto a la regulación de entrada, en respuesta a la demanda. Las últimas décadas han atestiguado un cambio decidido de la demanda de fuerza de trabajo para la agricultura y construcción, así como para servicios de hotelería, restaurantes, hospitales y alimentos, hacia un perfil laboral compuesto por profesionales con alto nivel de educación relacionado con la creciente demanda de servicios de software y trabajo intelectual altamente calificado y entrenado. Tal demanda ha crecido exponencialmente, tanto que el Programa de Naciones Unidas para el Desarrollo (PNUD), en 2001, identificó un problema importante: la fuga de cerebros constituido por una enorme pérdida para las economías y sociedades del Sur, no sólo de sus miembros más productivos - un problema de larga data-, pero los más altamente capacitados y educados, personas sobre los cuales se han invertido escasos, pero a la vez muy importantes "recursos", en los países de origen de los migrantes y que a la postre han sido "apropiados", de forma gratuita, por los países receptores de migrantes en el Norte, especialmente Estados Unidos, país que durante mucho tiempo ha sido el principal receptor mundial de este tipo de trabajo intelectual altamente calificado, y que, junto con otros países ricos, ha ido abriendo sus puertas a profesionales de los países en desarrollo a un costo muy alto para los países de origen. 
Este patrón de fuga de cerebros es un problema creciente en muchos países en vías de desarrollo, para los que implica el gasto e inversión de escasos recursos financieros en la educación y capacitación de los profesionales que emigran en gran número y agotan los recursos humanos más educados y valiosos. En el caso de India, por ejemplo, el PNUD documenta la migración de 100 mil profesionales a la industria de la computación de Estados Unidos en 2000, una cifra que se espera aumente a medida que el gobierno de Estados Unidos incremente el número de visas para profesionales de alto nivel. El PNUD calcula que el éxodo de profesionales con educación universitaria cuesta a India entre 15 mil y 20 mil dólares estadounidenses. por cada profesionista, es decir, hasta 2 mil millones de dólares al año, y esto solamente en una industria. El costo total para los países en desarrollo del Sur, en este tipo de emigración es asombroso, lo suficiente como para socavar seriamente las posibilidades de desarrollo económico en el país.

Este problema es evidente en el cambio que se ha producido en el patrón y la estructura interna de la migración laboral mexicana. Un segmento cada vez mayor de estos migrantes es universitario y altamente capacitado. En promedio, los migrantes mexicanos están mejor educados que los estadounidenses y, por tanto, representan un "recurso productivo" que se pierde casi por completo en México. Por lo menos, los migrantes de la clase trabajadora envían remesas a sus familiares y comunidades de origen. Sin embargo, hay indicios de que los beneficios económicos que se derivan de los más cualificados se acumulan casi totalmente en los países receptores de migrantes, como Estados Unidos, que no asumen ninguno de los costos importantes de reproducción de esta fuerza de trabajo. ${ }^{3}$

Una prueba más del problema de la fuga de cerebros proviene de la iniciativa y los esfuerzos concertados de las diversas agencias de la Organización de las Naciones Unidas (ONU), organizaciones no gubernamentales (ONG) de desarrollo y empresas de tecnología en 2002 para revertir la devastadora pérdida de profesionales con educación universitaria en África. La población objetiva de esta iniciativa incluye científicos, médicos, ingenieros, profesores universitarios, economistas, informáticos y otras personas altamente cualificadas que escasean en el continente.

\section{Maquiladoras, trabajo migrante y frontera México-Estados Unidos}

Estados Unidos es la nación con los más altos niveles de inmigración en el mundo -absorbe hasta el $20 \%$ de todos los migrantes internacionales documentados-y México es la mayor fuente de fuerza de trabajo migrante para ese país -representa el $27 \%$ del flujo mundial de esos migrantes-. ${ }^{4}$ Además, se estima que el flujo de trabajadores migrantes indocumentados de México a Estados Unidos puede ser igual al flujo de migrantes documentos.

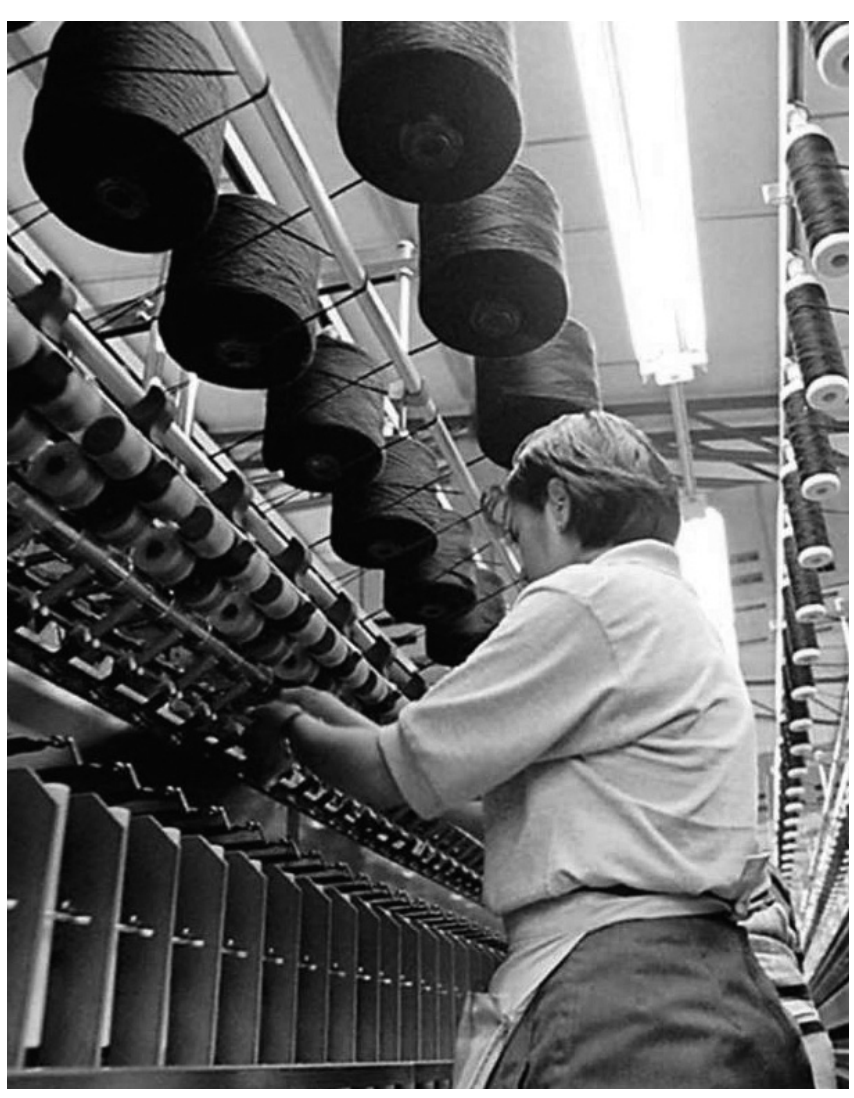

Hay varias razones para este enorme flujo; uno de ellos es el lamentable estado de la economía mexicana, la cual, se ha argumentado, se remonta, en parte, a las operaciones del capital estadounidense o las corporaciones multinacionales en el país. Las empresas estadounidenses y los bancos, durante la última década del siglo $\mathrm{XX}$, saquearon a México de sus recursos naturales y humanos, y realizado transferencias de hasta 100 millones de dólares en forma de ganancias, el pago de intereses a los bancos y de dividendos a los inversionistas de Estados Unidos. ${ }^{5}$

Un efecto colateral de este proceso y del Tratado de Libre Comercio de América del norte (TLCAN) - que ha sometido a cientos de miles de pequeños productores pobres y medianas empresas indígenas y de otra índole a las presiones de la competencia del "mercado mundial" (el Estado estadounidense subsidia las exportaciones) - ha sido una crisis de producción de enormes proporcionesque ha obligado a un número incalculable de mexicanos a abandonar sus comunidades y emigrar hacia Estados Unidos en busca de trabajo remunerado. Esto podría ser visto como una explicación "del lado de la oferta" para la exportación de fuerza de trabajo mexicana. En el otro lado está el mercado de trabajo en Estados Unidos, impulsado por un apetito voraz de trabajo barato. En este contexto, se estima que industrias enteras en Estados Unidos, así como varias economías del Sur, se vendrían abajo si no fuera por 
el suministro de trabajadores migrantes mexicanos documentados e indocumentados, quienes hasta hace poco se habían concentrado en dos sectores: trabajo agrícola, en su mayoría estacionales, y servicios, tanto en alimentos y bebidas (hospitalidad) y las industrias relacionadas, como en el subsector doméstico, que incluye, entre otros, trabajos de aseo y jardinería.

En la década de 1980, este patrón de exportación de fuerza de trabajo mexicana, que también puede ser identificado en otras regiones de la economía mundial, fue en cierta medida compensado por la exportación de capital estadounidense en forma de inversión productiva en plantas manufactureras que emplean capital de Estados Unidos y trabajo de México: el sistema de maquiladoras.

Un impulso importante detrás de la construcción de ese sistema es proporcionar una alternativa a la importación de fuerza de trabajo barata de México, o bien complementarla. ${ }^{6}$ En teoría, este proceso también se vería facilitado por el TLCAN; pero, en la práctica, el TLCAN ha funcionado para destrabar los controles de los gobiernos mexicano y canadiense, así como para ampliar el comercio internacional (la creación de una zona de libre comercio) y el libre movimiento de capital de Estados Unidos.

El TLCAN también ha fortalecido el movimiento de las empresas manufactureras estadounidenses para reubicar sus operaciones de ensamblaje en zonas y países cercanos a fin de aprovechar la mano de obra barata. Importar trabajadores en la industria implicaría el pago de salarios en una proporción hasta cinco veces mayor. A nivel mundial, esto ha resultado en una nueva división internacional del trabajo, así como en la creación de un sistema global de producción manufacturera integrada. En países como México, también ha dado lugar a la construcción, cerca de la frontera, de un amplio sistema de maquiladoras que emplea capital y tecnología estadounidense, y fuerza de trabajo mexicana, la creación de una plataforma industrial de exportación y una zona de libre empresa con relajadas condiciones laborales y ambientales para la operación del capital de Estados Unidos. En México, esto ha significado una enorme expansión de las exportaciones manufactureras, una de las mayores fuentes de divisas extranjeras, junto con la exportación de petróleo y las remesas de los migrantes.

\section{Comentario crítico y direcciones futuras}

El "desarrollo económico" derivado del crecimiento de las exportaciones no ha estado exento de costos económicos, sociales y ambientales. En cuanto a los costos sociales: la dependencia de este trabajo tiene consecuencias negativas para la salud de los trabajadores y pisotea el derecho a organizarse y sindicalizarse para luchar por la protección y promoción de sus intereses. El gobierno mexicano, en efecto -y lo mismo se aplica a las zonas de "libre comercio" o de procesamiento de exportaciones en otras partes del mundo-, dio una garantía al "capital" (propietarios e inversionistas) de que la maquila sería libre de sindicatos. Uno de los efectos de esta política ha sido la disminución de la capacidad de los trabajadores para negociar los salarios, lo cual se refleja en la reducción de los salarios que ha golpeado a los trabajadores en el sector de la maquila en los últimos años, presumiblemente en respuesta a las presiones de la competencia de las exportaciones chinas.

Otro costo ha sido la dependencia de puestos de trabajo en una industria controlada por extranjeros, haciendo vulnerable los trabajos y la economía en general a las vicisitudes del capital global. La evidencia de esta vulnerabilidad es la reciente tendencia a reubicar maquiladoras en países como China, que dispone de fuentes de trabajo aún más baratas. Mientras los trabajadores en México reciben alrededor del $20 \%$ del ingreso nacional en forma de salarios (en comparación con un rango de entre $30 \mathrm{y}$ $40 \%$ en muchos países europeos) los trabajadores chinos reciben aproximadamente el $6 \%$ del ingreso nacional, lo que permite que el gobierno chino orqueste una de las más altas tasas de ahorro e inversión en el mundo (40\%), un factor importante en el increíble récord de China de rápido crecimiento económico, con tasas de crecimiento de $10 \%$ anual durante más de diez años, cuatro veces mayor que la tasa realizada por los países industrializados, como Estados Unidos, y el doble de la tasa de crecimiento anual experimentada por cualquier país en el período denominado por los historiadores como "la edad de oro del capitalismo" (1948-1970).

Referencias

${ }^{1}$ Global Commission on International Migration (GCIM) (2006), en www.gci,.org/en/links.html; Stalker, Peter (2000), Workers without Frontiers, Boulder COL, Lynne Rienner.

${ }^{2}$ Delgado, Raúl, Humberto Márquez y Héctor Rodríguez (2009), "Seis tesis para desmitificar el nexo entre migración y desarrollo”, Migración y desarrollo, no. 12.

${ }^{3}$ Ibidem.

${ }^{4}$ Conapo (2004) Migración internacional. Revisado el 7 de enero de 2005 (http://www.conapo.gob.mx).

${ }^{5}$ Saxe-Fernández, John y Omar Núñez (2001), “Globalización e Imperialismo: La transferencia de Excedentes de América Latina”, en Saxe-Fernández et al. Globalización, Imperialismo y Clase Social, Buenos Aires/México, Editorial Lúmen.

${ }^{6}$ Cypher, James y Raúl Delgado Wise (2006), “Mexico's LabourExport Model: Globalization as Subordinate Economic Integration”, en Bowles, P. y Veltmeyer, H. (eds.), Globalization: National and Regional Perspectives, London, Macmillan Palgrave. 